\title{
Psychology and Non-sense: Schizophrenese as Example
}

Rupert Read 1ब

Email R.Read@uea.ac.uk

Bo Allesøe Christensen 2

1 University of East Anglia, Norwich, UK

2 Aalborg University, Aalborg, Denmark

\section{Abstract}

The abstract is published online only. If you did not include a short abstract for the online version when you submitted the manuscript, the first paragraph or the first 10 lines of the chapter will be displayed here. If possible, please provide us with an informative abstract.

In this chapter we will focus on the relation between psychology as a discipline and how it understands nonsense. We will present a broad Wittgensteinian perspective inspired by the approaches of Peter Winch and Rom Harré, and use Wolcott's approach to the 'language' of schizophrenia, schizophrenese, as an object of analysis. Using a therapeutic understanding of Wittgenstein, we will claim that Wolcott's approach resembles a substantial (Wittgensteinian) interpretation of schizophrenese, debarring an actual ('resolute') understanding of the nonsensical character of schizophrenese. In the end, we conclude that Winchian and Harréan approaches help develop our sensitivities towards the diversity and uniqueness of cultural practices, but that it can be misleading to assimilate severe mental disturbance to the concepts of culture and language. Doing so misunderstands and covers over such disturbance, in the very act of seeming/seeking to understand it.

\section{Keywords}

Non-sense

Wittgenstein

Therapeutic reading

Schizophrenese

\section{Introduction}

Often when we claim to understand something, we imply understanding the meaning of it. Hence, understanding a game of tennis is understanding the meaning of what is going on between the players, the judge and the audience. This going on can, of course, be framed theoretically in many different ways, depending upon whether one's focus is on structures, symbols, the material surroundings etc., with corresponding methods and theories providing the respective interpretative frame. Harré has been one of the precursors, along with Winch (1958) and others, arguing the importance of using Wittgensteinian methods and notions in facilitating an understanding of cultural psychological notions. The aim is not the production of endless vagaries of theories, but developing our sensitivities towards the diversity and 
uniqueness of cultural practices. In this sense, we can develop a description of the "grammar" of the practice of tennis by understanding how rules, norms and symbols are used by both tennis players and the audience. A grammar is thereby "... a conceptual system by the application of which a field of meaningful phenomena is brought into being" (Harré 2004, 1444). Knowing these conventions of tennis allows the audience to watch and understand what the players are doing in and as a tennis match, while also making tennis playable (alongside balls, net, rackets, a certain physique etc.), in a way unlike badminton, to the players themselves.

The connection between rules, norms, symbols and a specific practice outlines a meaningful space where, in the above case, tennis makes sense. Tennis thereby becomes a meaningful practice having a distinctive significance in contradistinction to other practices where other things are engaged with and rules used. Rules, norms and symbols in practice thereby provide in this way a space of non-sense as well, and it is this notion of non-sense we will focus on here. In one interpretation non-sense seems to be defined as the point where sense stops, as a space surrounding sense. Thus, tennis is not badminton. However, though the rules, practices and artefacts of badminton make no sense within a tennis game, they make sense on their own. So, despite it being non-sense to say "Tennis is badminton" we can make sense of why this is non-sense, by explaining the difference between these two sport activities. Paraphrasing the anthropologist Mary Douglas, we might say that non-sense is just sense out of place with the explanation providing non-sense with a place where it makes sense. Or, the explanation provides the non-sense with a sense we did not see before; it was (in) a sense "hidden".

We will ask whether this - we take it as a "common-sensical" perspective on how to understand the relation between sense and non-sense - is the right frame for understanding certain "non-sensical" cultural-psychological phenomena. And we will analyse Wolcott's suggestion of modelling the 'language' of schizophrenic people, schizophrenese, on (Wittgenstein's notion of) a solipsistic, private — and for all others - non-sensical language, (Wolcott 1970). ${ }^{1}$ Wolcott's interpretation of schizophrenese comes close to the frame just sketched: despite its non-sensical character we could actually interpret and explain schizophrenese so it makes sense. Our analysis, however, will show that Wolcott adopts a traditional way of understanding Wittgenstein, in contradistinction to a recent resolute/therapeutic interpretation of Wittgenstein. ${ }^{2}$ Using the latter, we will present a different picture of how a Wittgenstein inspired approach can inform our understanding of schizophrenese.

In the following we will, first, use a distinction coined by Stephen Mulhall, describing two interpretative strategies for understanding the private language argument, a substantial and a resolute. Second, we will describe Wolcott's interpretation of Schizophrenese as a non-sensical private language, involving a logico-syntactical strategy and question, 'therapeutically', the substantial nature of this strategy. This will recapitulate and supplement Read's interpretations of schizophrenia (Read 2012), and we will end with a brief comment on cultural psychology and non-sense exemplified by our Wittgensteinian interpretation of schizophrenia.

In sum: we shall argue that schizophrenese is not best heard as just another language-game. It does not stand as badminton does to tennis; nor can it even be adequately comprehended by imagining someone playing tennis according to the rules of badminton. Rather, one should be clear that there isn't anything well-defined that counts as imagining that. There is indeed no that there. Sense stands to schizophrenese as tennis does to nothing. To an absence of a game.

\section{Non-sense, Private Language and Schizophrenese}

It may help, at least at a first pass, to consider something like an idea of a private language in the context of schizophrenia. We can ask whether linguistic articulations like word salad or verbigerations amount to 
mere gibberish. Or if they are better characterised as a private language made up of words; or perhaps even better as meaningful units understandable only by the schizophrenic person uttering them.

Furthermore, we can ask, how we can know? Is "schizophrenese" as Wolcott terms it, something we might be able to consider meaningful in itself by providing a theory for it, or if not, how do we then come to an understanding of it?

Now, a useful distinction between substantial and resolute readings of the private language argument has been made by Mulhall (2007). It corresponds to the overall distinction between traditional and resolute/therapeutic readings of Wittgenstein noted above, and comparing it to Wolcott's interpretation it will provide us with some clues for understanding schizophrenese as a possible private language.

Mulhall $(2007,1)$ describes the substantial reading as distinguishing between nonsense and gibberish, with the former consisting of violations of logical syntax, by combining perfect legitimate elements but in an illegitimate way. So, for example, the concepts of sun, happy, the and is, are perfectly understandable in themselves, but combined as The sun is happy the sentence is non-sense. It is not gibberish, for while the sentence does not make any sense, it still has a grammatical form (as well as an argument form, $S$ is $H$, and a predicate logical form, $\exists(\mathrm{x}) \mathrm{Fx}$ ) which can be accounted for, by providing a theory of rules (and criteria for applying these rules) establishing the right conjunction(s) of the sub-sentential elements into sense-carrying sentences. Nonsense, then, is sense out of place; it is understanding that "happy" (or "sad") cannot be used about the sun, but is usable in other similar kinds of sentences.

For Mulhall $(2007,5)$, then, the substantive reading provides a theory of meaning "...a specification of the conditions under which a sentence makes sense..." thereby indicating that if we theoretically get the criteria, rules and grammar right for a piece of discourse, then we can also make sense of why it happens to be nonsensical, and conceive of possible future instances of its instantiation as well. Explicating rules, criteria and grammar then, shows how people makes sense and nonsense of a given piece of discourse. Within this interpretation one prominent way of taking Wittgenstein's private language argument (roughly PI\$243-326) allegedly shows that a language understandable by only one individual is incoherent, because whenever a piece of language-use is taken to be correct, it is correct in terms - not of whatever the individual makes of using the language personally but - in terms of the community of language users the individual is part of.

In Witherspoon's terms $(2000,315)$, this is a kind of Carnapianism, understanding how the use of words and sentences outside a proper "linguistic framework" lapse into nonsense. The meaning of a sentence is a function of the form of and concepts entering the sentence, just like the sentence above. Witherspoon $(2000,341)$ furthermore claims that Carnapianism in addition is committed to the thesis that the proposed meaninglessness of a sentence is a (quasi-)function of the same grammatical form as sensical sentences. Thus, the sun is warm and the sun is happy both have the same form, but is happy only has a quasifulfilling predicative role, since it does not contribute to the meaning of the sentence. Hence, we can reframe Mulhall's point above that by doing a logical-grammatical analysis we explicate how different quasi-predicate and quasi-subject roles are contributing to the meaninglessness of sentences as well. Readers will note that this substantial reading is similar to the common-sensical understanding of sense and non-sense introduced in the beginning, the difference perhaps being the former's more nuanced linguistic description. However, as Witherspoon notes, the point above turns out to involve a predicament. Providing such a substantial theory of meaning implicitly assumes that the realm of meaninglessness actually contains a rich structure. And this, as Witherspoon writes, implies that “...certain sentences are nonsense because of the kind of sense they have." (2000,342). Hence, the frame actually debars any possibility of understanding nonsense as what it is, namely non-sense. An absence of (a/any) sense. AQ1 
So basically, a substantial theory provides a meaningful explanation, by presenting a theory of meaning of what (the substance of) non-sense is. It is sense out of place (e.g. in the wrong game), for example being in the wrong place by not contributing to the meaning of the sentence in which it occurs. The resolute or therapeutic reading argues against this, claiming, according to Mulhall $(2007,5)$, that there are no ineffable insights about non-sense to be explained by providing a theory of meaning delimiting and recognising the intelligibility of the distinction between sense and nonsense. Rather, Mulhall characterises the therapeutic reading as "...the capacity to recognize when a sign has not been given a determinate meaning - even when it appears that it has been" Mulhall $(2007,7)$. Hence, the therapeutic reading can be understood as a process of elucidating something as non-sensical in a given situation without assuming a theory of sense or meaning explaining, or interpreting it. Nor is the making of a general theory of discriminating sense and nonsense to be the result of this elucidation. Instead the therapeutic reading claims that recognising the (at times) indeterminateness of meaning is a more correct Wittgensteinian point of departure, also when dealing with schizophrenese.

\section{Wolcott on Schizophrenese}

The aim of Wolcott (1970) is providing a new paradigm for the study and understanding of 'schizophrenese'. He uses schizophrenese to characterise utterances classifiable as neologisms, word salads or verbigerations (ibid., 127) The problem, then, is, when a person speaks schizophrenese, this person seems to be speaking a private language in a 'Wittgensteinian' sense, i.e. using words and sentences the meaning of which only this person knows. Can this person be understood and how?

Wolcott answers this by reframing it as involving three questions: is schizophrenese a language, and language is here understood in a logical-grammatical sense similar to the one described above, only Wolcott terms it a Reichenbachian sense: consisting of a set of signs plus vocabulary, whose use is dictated by (formation, truth and derivation) rules with criteria for the application of these rules (Reichenbach 1947); is schizophrenese a private language, with 'private' denoting signs and categories unshared with and unverifiable by others; and given schizophrenese, is intersubjectivity then possible, with intersubjectivity denoting a set of meaningful signs reciprocally shared. (ibid., 127) Wolcott thereby hopes to show that if schizophrenese is a language in the depicted sense, then it cannot be entirely private but must contain meaningful shareable elements. Furthermore, it will then be possible for other people (in casu the therapist) to make sense of schizophrenese.

Wolcott's approach therefore first outlines the conditions for a language to be meaningful. His theory of meaning presents a form for a language with a grammar consisting of concepts, rules and criteria for applying the rules, supplied with different linguistic functionalities. ${ }^{3}$ Furthermore, the hope is that in explaining schizophrenese as a piece of discourse using the theory of meaning, this will enhance our understanding of it by distinguishing between sense and nonsense, between joint-meanings and pure idiosyncratic meanings, with joint-meanings making a fruitful dialogue between speaker and listener possible. Wolcott therefore recommends that instead of encouraging the schizophrenic patient to speak schizophrenese, "... a stance that might implicate the psychiatrist in learning many varieties of schizophrenese, I would suggest that the psychiatrist should seek to get the patient ultimately to use ordinary language.” $(1970,133)$ Claiming that ordinary language “...is more efficient, more logical, and more conducive to linguistic competence than schizophrenese" (ibid., 133) and therefore more recommendable is inevitable, if we recall Mulhall and Witherspoon's arguments above. Schizophrenese is sensical within the theory of meaning Wolcott proposes, because it delineates a distinction between sense and nonsense, and explains how schizophrenese as nonsense makes sense here. Hence, it is less about recognising the indeterminateness of meaning in Mulhall's sense, than subsuming it under the pre-given theoretical projection of language and sense proposed. In other words, and a point we will return to later, 
Wolcott's psychiatrist above is actually taking a position external to the context where schizophrenese occurs, not really recognising or engaging with what is actually said. This is because Wolcott's analysis is foundering on the same cleft stick that afflicts the substantial theory/reading of nonsense: One claims to say what the nonsense means, and thus inevitably undercuts its status as nonsense, and moves outside the space of any person who in fact has uttered nonsense.

Wolcott's analysis 'shows' that schizophrenese makes sense because it resembles a language: it has rules of assonance, association and metonymy for establishing word meaning, as well as rules of concretion, asyndeton and disjunction for sentence meaning. These rules are, furthermore, applied according to the following criteria, continuity, "Once schizophrenese is systematized into a private meaning system, the rules are kept." (ibid., 132), and contextual appropriation, i.e. if the context is right the rules are likely to be applied. Furthermore, it is also a private language in what Wolcott takes to be a 'Wittgensteinian' sense, i.e. a language referring to private objects which are inner, unknown and unshared by others. 'Despite' this, intersubjectivity is still theoretically possible through joint-meanings, i.e. by the patient and the psychiatrist referring to the same noun-phrases or verb-phrases, or upholding a continuous dialogue keeping to the same general topic. Thus, the statement "666-sick sick sick" is considered a private schizophrenese statement, an instance of assonance "...more readily decoded by the receiver. But the equation of the number " 6 " with the adjective "sick" remains a private word-meaning. It is an instance of a token or unique connotation of a sign" (ibid, 130) Wolcott is here implying that despite the sentence failing to make any sense (it is private), its meaninglessness still contains an explainable rich structure. Thus, using his model for what a language is, he can 'explain' schizophrenese and its syntactical rules and criteria. This strikingly resembles the substantial reading presented by Mulhall above that if we theoretically establish the criteria, rules and grammar for a piece of discourse, then we can make sense of why it happens to be nonsensical and conceive of possible future instances of its instantiation as well (cf. Wolcott's idea of continuity and context of appropriation).

After this characterisation of Wolcott's substantial reading of sense and nonsense as related to the use of schizophrenese, let us move on to how a therapeutical reading understands this.

\section{What Would the Therapeutic Point Be Then?}

Let us take stock. By approaching schizophrenese in a logico-syntactical way, Wolcott ends up in what resembles a paradoxical position, that the apparently nonsensical is actually sensical. The person speaking schizophrenese can be still understood because schizophrenese follows, similar to other kinds of languages, rules and criteria for applying these rules. Thus, schizophrenese makes sense and displays a quasi-logical structure, despite the admission it is non-sensical. What would the therapeutic vision be of the preliminary diagnosis above? Well, it wouldn't try to replace Wolcott's proposal of a theory of how schizophrenese makes sense with yet another theory, but recognize that in the case of schizophrenese it might not make sense at all! This possibility has to be held open: that in some cases, we cannot succeed in attributing sense to something without 'violating' it, without turning it into something it is not. (This is what Wittgenstein thinks, of some instances of philosophical nonsense: that they are irreparable without becoming something other than what their utterer wanted them to be. That the utterer has irreconcilable desires with regard to her words, and is not aware of this; see Read 2001, 463.)

Our analysis above shows that Wolcott's theory of meaning is incapable of recognizing the indeterminateness of meaning, because it depicts non-sense in a very sensical way, by presenting a logicosyntactical frame for it before engaging with it. It is this which makes Wolcott's (and the psychiatrist he refers to) position external; it resembles an explanation or interpretation of how schizophrenese "really" works, carried out from the outside. However, that shouldn't make us succumb to theorizing about engagement (as if asking how it really works from the inside) as the way forward either. For the 
therapeutic approach analysis and description is 'therapy' enough, and we might add two clarifying therapeutic points using Read's investigations of different perspectives on schizophrenia. First, that any understanding of schizophrenese will have to match the self-understanding of the person using it (and that such understanding therefore will not be feasible if there is no possibility of a successful selfunderstanding on which to base it). Second, that schizophrenese in at least some (radical) cases most likely cannot be understood because it simply has no content, it is non-sense. (The two points, obviously, are linked.)

Firstly, Read has in different places (e.g. Read 2001, 2012) discussed and criticized interpretations of schizophrenia invoking the concept of nonsense as well as solipsism, insofar as those interpretations presume that what they result in must actually make a kind of sense. For such a mode of hermeneutics is self-contradictory. Nonsense is nonsense.

What, then, would the right approach for understanding schizophrenia be? Read (2001) starts out by following Winch $(1958,1964)$, claiming that a sound approach, when we speak about human sciences like psychology, should at least be based on an unimpositional analysis and "...description of, roughly speaking, the self-understandings-in-action of the people or person one is studying" (Read 2001, 456). One avoids thereby, hopefully, disturbing the description and analysis of people's practices as they themselves understand them, i.e. not altering the norms, or rules they are following. Instead one aims for the simple criterion that the analysis and description can be accepted by those described. Unlike Wolcott's proposal of a theory of meaning, interpreting and explaining these practices by making a representation of them, i.e. imposing a certain model, Winch would have us look at what is going on. We would thereby present an analysis and description matching (as far as possible) the self-understanding of the people engaging in these practices. So, the example above, "666, sick-sick-sick", is interpreted by Wolcott as representing a quasi-logical way of expressing a verbigeration. But this might be too quick a "deciphering" of schizophrenese, as claiming what is "really" going on. We need to consider whether it even makes sense to model schizophrenese on a (quasi-)logical way of speaking, as well as the following question: does this logic (or any other logic) match the self-understanding of the person expressing this? Can we even speak of self-understanding when it comes to a person speaking schizophrenese? Is there a way of deciphering 'schizophrenese' which does not turn it into something far too much like the language of those not subject to the radical (self-)disorder of schizophrenia?

This move of Read's can be read as a kind of radicalisation of the warning that Winch famously makes against covertly turning Azande discourse into something easily domesticable into English language and culture.

From a Winchian perspective Wolcott's approach is therefore predominantly over-intellectualist, suffering from what we might call a 'logicalist' bias: assuming the person investigating schizophrenese to be chiefly a logician or theorist of meaning, and the investigated person as engaging in a quasi-logical endeavour the therapist can systematically explain. This bias blocks Wolcott from "seeing" cases (in their own terms) of schizophrenese so bizarre or recalcitrant they cannot be understood, or explained at all. It is simply impossible to assume (without violence or imposition) overall that schizophrenese as an expression of a schizophrenic's self-understanding can be understood within any logico-syntactical frame. It excludes the aforementioned indeterminateness of meaning; the "... arbitrarily many ways of describing (or "interpreting") — and thus, unmisleadingly expressed, none" (Read 2001, 460). Hence, we might as well claim here, that there actually is nothing to understand. So, a Winchian approach thus extended would make us more sensible to the acceptance that our descriptions might very well make us realize that there might be nothing to describe. Especially because of the likely impossibility of seriously addressing any affirmation the schizophrenic could make of our putative description. Indicating this, Read presents cases of severe schizophrenics where a successful interpretation, it would seem, simply cannot occur, 
because “...there simply aren't, here, any true self-understandings available” $(2001,461)$. For: Such a true understanding would imply the emergence from and decisive leaving behind of the schizophrenia.

Accepting this we might still imagine the possibility of asking whether schizophrenese then is more like a case of solipsism, i.e. the person speaking it making up a meaningful private language (like a private linguist) but unable to express this meaning to others?

Analysing and critiquing this possibility, Read follows Conant (1991) and Diamond's (1991) reading of the early Wittgenstein's thoughts on non-sense and solipsism. ${ }^{4}$ This reading centers, in a way, on a specific remark by Wittgenstein (Tractaus 5.62) (Read 2001, 466) stating that what solipsism correctly means cannot be said, but must instead show itself. This could be read as indicating that the schizophrenic's "world" can only be shown focusing on the limit of schizophrenese against "normal" use of language; i.e. the limit of the schizophrenic's language is the limit of the schizophrenic's world. This, however, may lead us to think that schizophrenese makes sense within a solipsistic 'world'. It is then allegedly just a different form of language compared to "normal" language, and we are unable to express its inherent meaning (using our normal language) without making it sound like nonsense, "...we are inclined to believe that it is something that retains ineffable truth, even if we (as it were) unfortunately happen to be unable to state it" (Read 2001, 466). So, what we have here is the temptation to reify schizophrenese as a meaningful phenomenon. Only its sense is hidden and must be brought out ('shown') using means of expression other than normal language, e.g. Wittgenstein's developed logic in the Tractatus, or as in our case, Wolcott's logico-syntactical expression. So, then we would have here a new version of Wolcott's line of thought.

Following Diamond and Conant, Read argues this is not how Wittgenstein's remark (or the purpose of Tractatus) is to be understood. Instead the purpose of the Tractatus is to convince us that the logic 'cannot' show what cannot be said, because there is nothing to show: "Diamond et al. seek to understand the logic of the Tractatus - while leading up to the conclusion that it has in a vital sense no logic whatsoever. TLP's "logic" is a "logic" of illusion, of what we are inclined to believe, of a set of psychologically attractive but ultimately empty pseudo-claims..." (Read 2001,464). The implication of Diamond and Conant's reading, then, is that the remark above (Tractaus 5.62) is not claiming a truth to solipsism, which unfortunately is unstateable. Rather, "Solipsism, is merely a name for a certain set of logical temptations, temptations from which we can potentially be delivered, once we cease to think of "it" as retaining a truth at all behind its "front" of non-sense" (Read 2001, 466). So, and this brings us to the second point, schizophrenese has no content, there are no logico-syntactical structures to be systematically comprehended or explained. It is simply non-sense. Einfach unsinn, in Wittgenstein's terms.

Hence, this aligns with a Wittgensteinian view on non-sense, that there is nothing to be learned from it, because there is nothing in it. It is only a nothing that masquerades as a something. Schizophrenese, thus, "...can be most properly viewed as plain non-sense-something with which nothing can (as yet) be done..." (Read 2001, 466). This therapeutic point is, that there is, we strongly suspect, simply no logicosyntactical "truth" or meaning within schizophrenese for us to discover or handle. Proposing a theory of meaning explaining "word-salad" or "verbigerations" cannot capture an essential logical structure behind the proposed non-sense of schizophrenese, because our best conclusion must be that no structure exists. The therapeutic approach therefore helps us resist the temptation of assuming an inherent structure or even system. Instead, "There is simply nonsense: pseudo-sentences, forms of words, etc. for which we have not as yet found a use, and as of now literally cannot imagine so doing" (Read 2001, 467).

Schizophrenese therefore is clearly best not characterized as a language. 'It' might be private (if we can describe the person speaking it as having a sense of privacy; or at least an 'inner world'; though below we shall question even that) but not as a language. The person is not a private linguist; as Wittgenstein sought 
to teach us, there isn't anything that can satisfactorily be designated as such a thing. The profound failure of most readings of Wittgenstein's 'private language' discussions is that they in effect assume that a 'private language' IS a language. Rather than realising that, Wittgenstein meant us to come to see that the temptation to so much as imagine that we can imagine a private language is the very non-sense that possesses us.

If we were forced to describe 'schizophrenese' as logical it would be patho-logical, suffering from the illusion of being like a language with a meaningful structure behind its non-sense.

The suffering of schizophrenia in certain impenetrable cases may indeed be just this: that, far from being locked in a world that one cannot communicate to others, one might be said to lack even the consistency of a world. One would then lack anything stable to communicate. The tragedy then would be of a grimmer nature than unreachability or 'ineffability'. For if that were the best way to understand the situationunderstanding the absence of there being something to understand - then the absence of a language would correlate with the absence of a world.

There $i s$ then a sense in which the would-be speaker of 'schizophrenese' resembles the 'private linguist'. But the sense is radical indeed: they resemble each other in that we have not been given good reason to believe that they can possibly exist, and have good reason to believe that there isn't any such thing as them doing so. The schizophrenic whose discourse resists a non-impositional, non-imperialistic serious and empathetic effort to understand is then like the 'private linguist'; they are someone whose words do not add up to anything. There is more to humanity, it would seem, than is dreamt of in Wolcott's proposal: we should hold open the possibility that in cases of sufficiently serious psychopathology, there is no 'private language', because there is no language. There is only a tragic simulacrum of it. A perpetual desire, perhaps, to speak. To communicate. But only the would-be forms of such a content that would want, hopelessly, to be speakable. Nothing ineffable to say.

\section{Coda}

Our discussion here has not been a discussion of schizophrenia as a clinical phenomenon, though obviously our hope includes that it might have hints or implications for such a discussion. Instead we have followed the tradition of Sass (1992) change to Sass (1992, 1994), and Wolcott (1970) before him, claiming that something philosophically significant and relevant can be expressed about schizophrenia by invoking a Wittgensteinian perspective. Against their more substantial understanding of Wittgenstein, we have presented the advances of a 'therapeutic' reading inspired originally by people like Peter Winch and Rom Harré. Arguing against the possibility of interpreting or explaining what really lies behind the nonsense of schizophrenese, what we can learn from extending the therapeutic approach and of Wittgenstein and Wittgensteinians like Winch and Harré is finetuning our analytical and descriptive sensibilities towards the diversity, contextualized nature and hence non-substantiality of certain psychological phenomena. Broadening our interpretive horizon beyond the sense-making limit imposed by traditional hermeneutics, to take in the radical possibility we think implicit in a resolute reading of Wittgenstein: that the right way to understand (sic) some philosophical urges, and probably, as we have sketched, some somewhat analogous psychopathological experiences, is to be clear that there isn't any there with enough stability or substantiality TO understand. And that to presuppose that there must be is to be captured by a dubious philosophical ideology that risks projecting and imposing a false sense.

AQ2

If so then we can understand why we might well not understand - that's the sense of understanding we would attribute to Winch as an extension of his approach - without having to presuppose that it will always make best sense to go on trying to understand. Even if the human thing to do still feels like it will 
be to go on trying, and not giving up on a fellow-human.

\section{References}

Baker, G. (1998). The private language argument. Language \& Communication, 18, 325-356.

Conant, J. (1991). Throwing away the top of the ladder. The Yale Review, 79, 328-364.

Diamond, C. (1991). The realistic spirit. Cambridge, MA: MIT.

Harré, R. (2004). Discursive psychology and the boundaries of sense. Organization Studies, 25(8), 14351453.

Mulhall, S. (2007). Wittgenstein's private language. Oxford University Press.

Read, R. (2001). On approaching schizophrenia through Wittgenstein. Philosophical Psychology, 14(4), 449-475.

Read, R. (2012). Wittgenstein among the sciences. England: Ashgate.

Reichenbach, H. (1947). Elements of symbolic logic. New York: The Free Press.

Sass, L. (1992). Madness and modernism. New York: Harper and Collins.

Sass, L. (1994). The paradoxes of delusion. Ithaca, USA: Cornell University Press.

Sullivan, G. B. (2017). Wittgenstein's philosophy in psychology. Interpretations and applications in historical context. Hampshire, UK and New York, USA: Palgrave Maemillan.

Witherspoon, E. (2000). Conceptions of nonsense in Carnap and Wittgenstein. In A. Crary \& R. Read (Eds.), The new Wittgenstein (pp. 315-349). London and New York: Routledge.

Winch, P. (1958). The idea of a social science and its relation to philosophy. London: Routledge.

Winch, P. (1964). Understanding a primitive society. American Philosophical Quarterly, 1(4), 307-324.

Wittgenstein, L. (2009). Philosophical investigations. (PI) (Revised edition by P. M. S. Hacker and J. Schulte). Malden, MA and Oxford, UK: Wiley-Blackwell.

Wolcott, R. H. (1970). Schizophrenese: A private language. Journal of Health and Social Behavior, 11(2), $126-134$.

We mostly bracket Wittgenstein here, because though Wolcott refers to Wittgenstein as inspiration, he does not discuss Wittgenstein's argument in detail. Hence, our focus here is neither on the many existing interpretations of Wittgenstein's idea of a private language, nor the validity of Wolcott's interpretation (for a general overview, readers should consult Baker 1998). We assume, in a certain sense along with Wolcott, that schizophrenese can be understood (sic) as a private language, and our "therapy" 
revolves around whether his approach or strategy is viable.

However, it will be self-evident to an informed reader that our approach relies heavily on Wittgensteinian thinking, and the usefulness of Wittgenstein's own thinking in relation to the matter we are describing will emerge into prominence as this paper unfolds.

Some Wittgenstein interpreters distinguish between a resolute and therapeutic reading of Wittgenstein. Since this distinction has no bearing for our argument, we use resolute and therapeutic interchangeably.

Wolcott also follows Reichenbach in distinguishing a cognitive and instrumental functioning of language, with the former being the use of language expressing true statements, while the latter is for the purpose of influencing another person. In addition, the instrumental can be divided into three sub-functionalities: communicative, suggestive and promotive. "Communication involves the transmission of meaningful messages to someone else with the aim of having him believe the information. Suggestion is the use of language with the intention of arousing emotions of another. The promotive use of language involves the intent of inducing another to perform certain actions." (ibid., 126).

Similar to Mulhall's distinction between a substantial and therapeutic reading above, some Wittgenstein interpreters suggest a substantial break in Wittgenstein's thinking between the early (Tractatus) and late works (Philosophical Investigations), while others emphasise the continuity in Wittgenstein's use of the therapeutic approach. Conant and Diamond are on the continuity side, hence their interpretation of non-sense and solipsism in the Tractatus relates to the late work as well. The logic of their radical mode of interpretation extends to the logic of the anti-'private-language' considerations. 